\title{
Assessment of agricultural potential of a river command using geo-spatial techniques: a case study of Himalayan river project in Northern India
}

\author{
M. P. Akhtar ${ }^{1}$ (D) L. B. Roy ${ }^{2} \cdot$ K. M. Vishwakarma ${ }^{2}$
}

Received: 30 March 2019 / Accepted: 18 February 2020 / Published online: 2 March 2020

(c) The Author(s) 2020

\begin{abstract}
Agriculture and associated sectors are one of the primary sources of living for the global population. Sustainability in agriculture will yield long-term benefits requisite to accomplish development and mitigation of resource scarcity. Hence, realistic assessment of water requirement for agricultural use or alternatively agricultural potential from available water resources is imperative to sustainable water management keeping in view of possible scarce situation in relation to freshwater availability across the Globe. The present study focuses on assessment of the water requirement for potential agricultural use for the command area of a Himalayan river project, namely Gandak river project in Northern India using extensive geo-spatial techniques. Detailed information of extensive canal network is derived from high-resolution satellite images using GIS tools, along with other spatially distributed information for relevant parameters such as rainfall, temperature, soil type, elevation, water-holding capacity and agricultural productivity. The study reasonably identifies the spatial variability in water requirement potential in the project command with rational indication of maximum water demand in north-central section of the study area where the lowest aridity index characterized by very low slope and deep sandy loam soil is recorded. Efficient usage with growing scarcity of this essential natural resource warrants efficiency optimization of water usage with realistic assessment. This approach unlike traditional method uses high-resolution satellite data that are more scientific and accurate and will undoubtedly facilitate development of rational decision support system for efficient management of available surface water use for different purposes in the region.
\end{abstract}

Keywords Floods · Water management · Aridity index $\cdot$ Evapotranspiration $\cdot$ Irrigation potential $\cdot$ Remote sensing and geographical information system

\section{Introduction}

A sustainable water resources management will facilitate sustainable agricultural productivity. Hence, it is important that the realistic assessment with regard to water uses for the limited available water resource must be carried out with adequate future planning. Global environmental challenges too have created a pressure for efficient management

M. P. Akhtar

parwez.akhtar@jaipur.manipal.edu

1 Department of Civil Engineering, School of Civil and Chemical Engineering (SCCE), Manipal University, Jaipur, Jaipur 303007, India

2 Department of Civil Engineering, National Institute of Technology Patna, Patna 800015, India water usage in bulk (Ahmad et al. 2013). The Himalayan river, namely Gandak with its catchment, is one of the oldest inhabited places in the world located in Himalayan foot hills within Indian subcontinent. Climate is major reasons that made this region a major agricultural hub through utilization of surface water available from the associate river basins. The climatic conditions can be divided into four segments: summer, winter, monsoon and post-monsoon. Winter season is marked with low temperatures and may be as low as $5-10{ }^{\circ} \mathrm{C}$, whereas summer is marked with high temperature. This region has a reasonably good rainfall that significantly contributes to agriculture and fisheries sectors.

Numerous studies have been reported globally, where water requirement for agricultural use has been attempted using geo-spatial techniques. Magd and Tanton (2005) analysed satellite images of Central Asian region in conjunction with field data of cropping pattern of a large irrigation 
scheme. The crop evapotranspiration (ET) of the different crops was computed from local field climatic data using the Penman-Monteith method of predetermined crop water requirements as used in Food and Agriculture Organization (FAO) CROPWAT program. However, satellite data were used apparently only for network visualization. Magd and Tanton (2005) established that the amount of water being used by the crop could be useful to analyse where water was being wasted. Using geo-spatial techniques, many works have been reported such as Chatterjee et al. (2005) where study on the groundwater flow modelling was conducted to assess waterlogged areas. Melesse et al. (2004) have worked out on accurate representation of the geology of the land covering the watershed required for understanding intricate hydrologic processes, since the expanse and type of watershed cover affects the hydrologic cycle using satellite data-based land cover information with high-temporal frequency and spatial accuracy. Satellite data-based estimation of surface evapotranspiration that significantly affects the water availability was reported by Singh et al. (2007) using operational characteristics and performance of the surface energy balance algorithm for land (SEBAL) model. SEBAL model, soil heat flux and sensible heat flux were utilized in order to compute surface evapotranspiration $(E T)$ on a large scale in the great Himalayan plains taking consideration of its variable climatic conditions. Furthermore, assessment of surface and sub-surface waterlogged area was reported by Chowdary et al. (2008) in the state of Bihar under Indian Territory, covering part of Himalayan river basins using geo-spatial techniques. For that, georeferenced data were acquired and waterlogged area were mapped with categorizing as surface inundation (seasonal), perennial water logging, saturated profile (seasonal) and saturated profile (perennial). Al-Ghobari and Mohammad (2011) presented the case for water conservation using intelligent irrigation system (IIS) application technology in arid region. Ismail et al. (2012) have reported a study on analysis of spatial distribution of physical and chemical properties of soil type to further produce three land utilizations. They analysed related LANDSAT (Land Remote Sensing Satellite), DEM (Digital Elevation Model) and data verification in conjunction with in situ observation with global positioning system $(G P S)$ assistance for classified delineation of the main physiographic units. Chatterjee et al. (2003) conducted a minor study on pre-monsoon and post-monsoon surface waterlogged areas and those were delineated using satellite data for three districts, namely Muzaffarpur, Vaishali and Saran districts of North Bihar under Himalayan plains. Digital data of IRS-IC LISS-III (Indian Remote Sensing-Linear Imaging Self Scanning Sensor-III) sensor acquired for the period, 1998-1999, were analysed using GIS tools. Using the modelling technique, a pixel was classified as water if the digital number $(D N)$ value of its near-infrared $(N I R)$ band is less than the $D N$ value of the red band and the green band, and the normalized difference water index $(N D W I)$ is greater than or equal to 0.32 . Inamdar et al. (2016) have analysis to assess irrigation and agriculture potential for Krishna river basin $(K R B)$ using geo-spatial techniques. Krishna river happens to be a peninsular river. More recently, Al Barik et al. (2017) reported a work on hydroelectric and irrigation potential of Dikhow river, Assam, that is a trans-Himalayan river. Das and Pardeshi (2018) stressed the importance of remote sensing and GIS techniques as a comprehensive tool for assessment of water resources including water management and conservation. In their study, remote sensing and GIS techniques are taken into consideration for zonation of different groundwater prospects of Pravara basin in India. More recently, Gebremedhin et al. (2018) reported an assessment of spatial distribution of aridity indices in Raya valley, northern Ethiopia. They firstly assessed the statistical properties of each aridity index at each station and further applied inverse distance-weighted geographic information system interpolation technique for the spatial estimation of the aridity indices.

However, investigations and insight looking into assessment of water requirement for agricultural use (alternatively assessment of agricultural potential) in the command of a specific Himalayan river (that too has a reasonable good rainfall and contributes considerably to the agriculture and fisheries sectors) with an extensive use of remote sensing and GIS application techniques are hardly found in the literature. In view of the above, the objectives of the present work are set as follows:

(a) to identify significant indicators that enhance the land cover mapping beyond conventional unsupervised classification of the visible/short wave bands for realistic assessment of land classification influencing water requirement and thereby agricultural productivity of the study area.

(b) realistic assessment of irrigation potential as well as agricultural potential that will account for realistic assessment of water requirement in command area of the Eastern Gandak Project using latest geo-spatial techniques.

To begin with, this paper first discusses indicators those used for assessing water requirement for potential agricultural use. Using GIS tools, digitization of canal network and delineation of study area are carried out through image processing in order to extract valuable relevant spatial data. The surface temperatures are derived from the thermal band of LANDSAT images in combination with normalized difference vegetation index (NDVI). The usefulness of spectral signatures in thermal and near-infrared spectrum is analysed with a view to boost land cover mapping and discriminate 
land cover classes. In particular, the surface temperatures and NDVI were helpful for delineating boundaries between wetlands and water bodies and between upland and wetland forests. Furthermore, using the enhanced land cover mapping and land cover classes, more realistic assessment of water requirement was computed using a software, namely CROPWAT and the statistical analysis were carried out.

\section{Study area and data extraction}

This study is carried out in two steps: The first step involves computation of irrigation potential (IP), and the second step concludes computation of associated agricultural potential in the study area. A detailed stepwise procedure has been presented in Fig. 1 in flow chart form (Kumbhar et al. 2014).

In the current study, Google earth pro-software has been utilized for digitization of canal network and delineation of study area. ARCMAP software has been used for image processing to extract usable geo-spatial data. CROPWAT was used to calculate crop water requirement, and the statistical analysis was carried out.

\section{Irrigation potential (IP)}

Irrigation potential is defined as the total gross area proposed to be irrigated under different crops during a year by a scheme in its command area. The area proposed to be irrigated under more than one crop during the same year is counted as many times as the number of crops grown and irrigated. To estimate the irrigation potential, digitization of the canal system from CARTOSAT imageries as well as command network ranging from main canal, over the distributaries to minors and sub-minors, was worked out. In this way, irrigation potential for the Tirhut Main Canal (TMC) of total $241 \mathrm{~km}$ of length with associated prospective canal network was predetermined using the generalized formula (Eq. 1) mentioned as follows. For this CARTOSAT-1, satellite data were acquired from National Remote Sensing Centre Govt. of India (NRSC). The study area did not cover in one scene; hence, images were assembled using mosaic GIS tool for obtaining a single satellite image for the study area and digitization of canal network was carried. The successive development of mosaic images and corresponding digitized canal network is presented in Fig. 2.

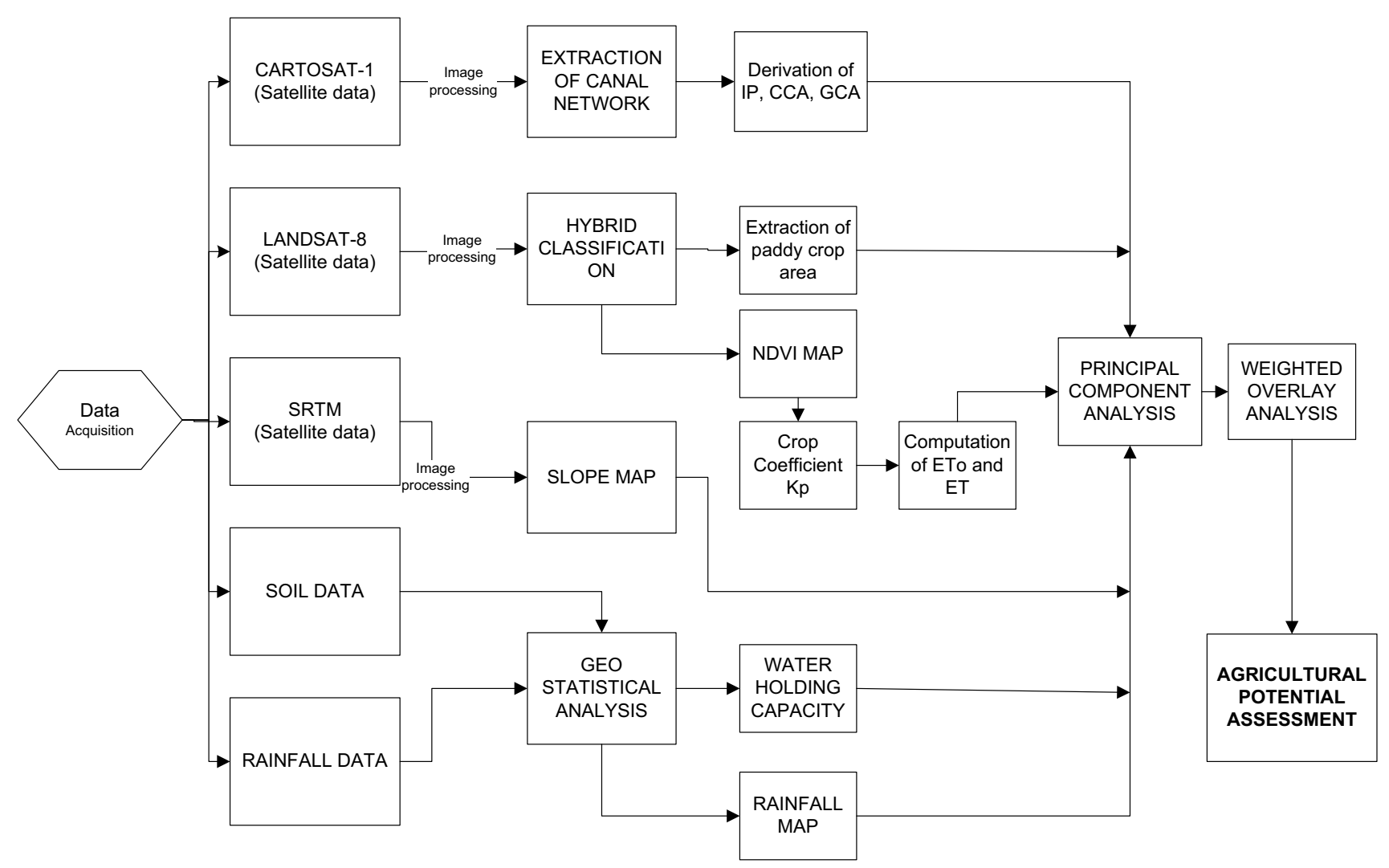

Fig. 1 Flow chart showing stepwise procedure for the present study 


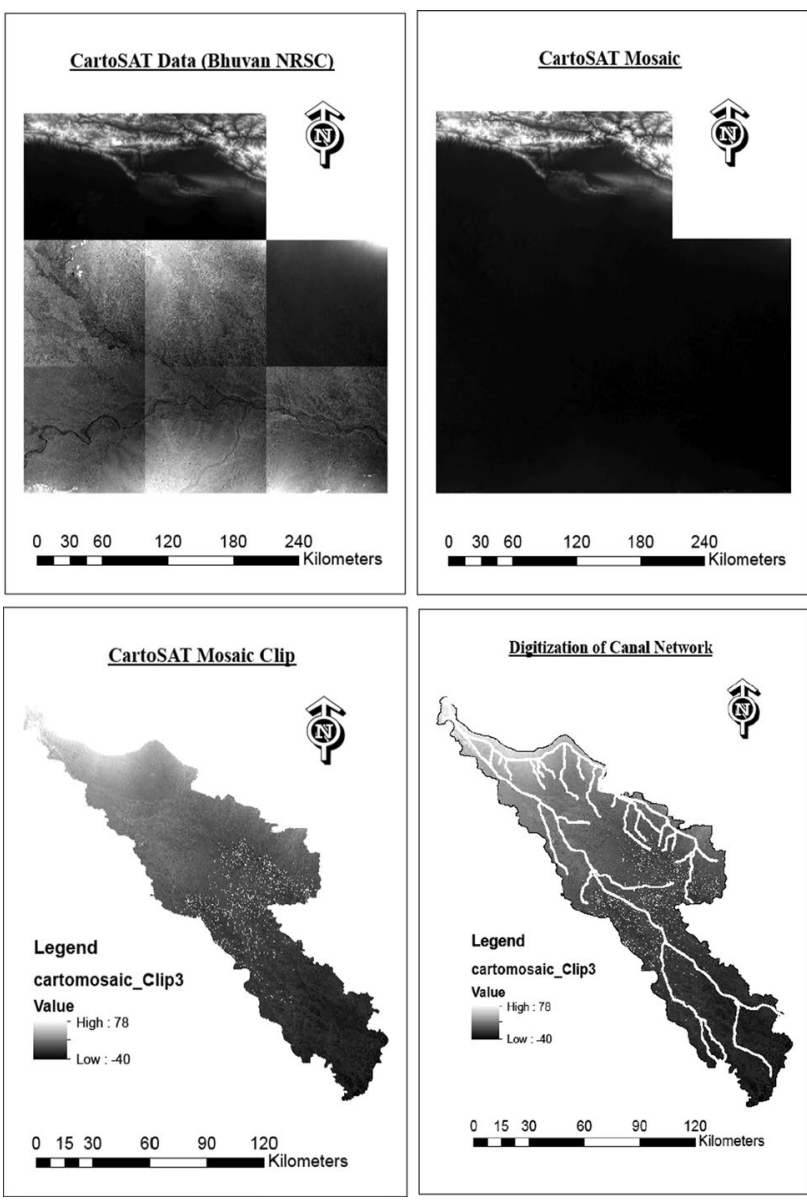

Fig. 2 Irrigation potential using CARTOSAT-1 scenes

SatelliteassessIP $=$ ProposedIP $* \frac{\text { Satellite derived length }}{\text { Field reported length of canal }}$

Using Eq. 1, canal lengths for respective canal type were derived from the image compared with proposed lengths and satellite data-based $I P$ is computed (Table 1).

\section{Agriculture potential (AP)}

As per the Food and Agriculture Organization (FAO), any assessment of potential agricultural use should focus on several basic issues. Agriculture encompasses arable use (the growing of the widest possible range of annual crops), horticulture (perennial crops in general and fruits in particular), pastural use (grass land and fodder crops and silviculture (commercial growing of trees). In line of that, potential use for paddy crop was assessed based on six different parameters such as irrigation potential $(I P)$, aridity index $(A I)$, precipitation, soil, slope and productivity of crop for the study area.

\section{Aridity index $(A I)$}

To compute agriculture potential, the first parameter which was considered is aridity index (AI). Aridity index $(A I)$ indicates the degree of dryness of the climate and can be computed using the following correlation.

$A I=\frac{P}{E T_{0}}$

where ETo is the potential evapotranspiration and $\mathrm{P}$ is the average annual precipitation (UNEP 1992; Camilo 2003).

\section{Slope}

In order to quantify slope, shuttle radar topography mission (SRTM) images using with crescent theory were utilized. The spatial cut and try of the image were done using slope instrument tool in ArcGIS software in order to develop integrated slope map for the study area. The stepwise developed slope map for the study area processed from SRTM satellite data is presented in Fig. 3.
Table 1 Assessment of canal wise (main canal/branch canals) satellite-derived irrigation potential

\begin{tabular}{lclcc}
\hline Name of canal & $\begin{array}{l}\text { Satellite-derived } \\
\text { length }(\mathrm{km})\end{array}$ & $\begin{array}{l}\text { Proposed canal } \\
\text { length }(\mathrm{km})\end{array}$ & $\begin{array}{l}\text { Proposed IP } \\
\text { (thousand ha) }\end{array}$ & $\begin{array}{l}\text { Satellite IP } \\
\text { (thousand ha) }\end{array}$ \\
\hline Tirhut Main Canal & 241.00 & 240.8 .0 & 542.00 & 542.50 \\
Triveni Branch Canal & 147.00 & 145.00 & 119.00 & 121.00 \\
Ghorsharan Branch Canal & 87.80 & 88.00 & 47.40 & 47.30 \\
Sugauli Branch Canal & 17.30 & 17.00 & 40.00 & 41.00 \\
Jamunia Branch Canal & 32.10 & 32.00 & 40.00 & 40.00 \\
Vaishali Branch Canal & 47.00 & 47.25 & 63.00 & 63.00 \\
Jaitpur Branch Canal & 34.30 & 34.45 & 23.50 & 23.40 \\
Mallikpur Branch Canal & 24.00 & 28.00 & 53.50 & 46.00 \\
& & & Total & 923.20
\end{tabular}




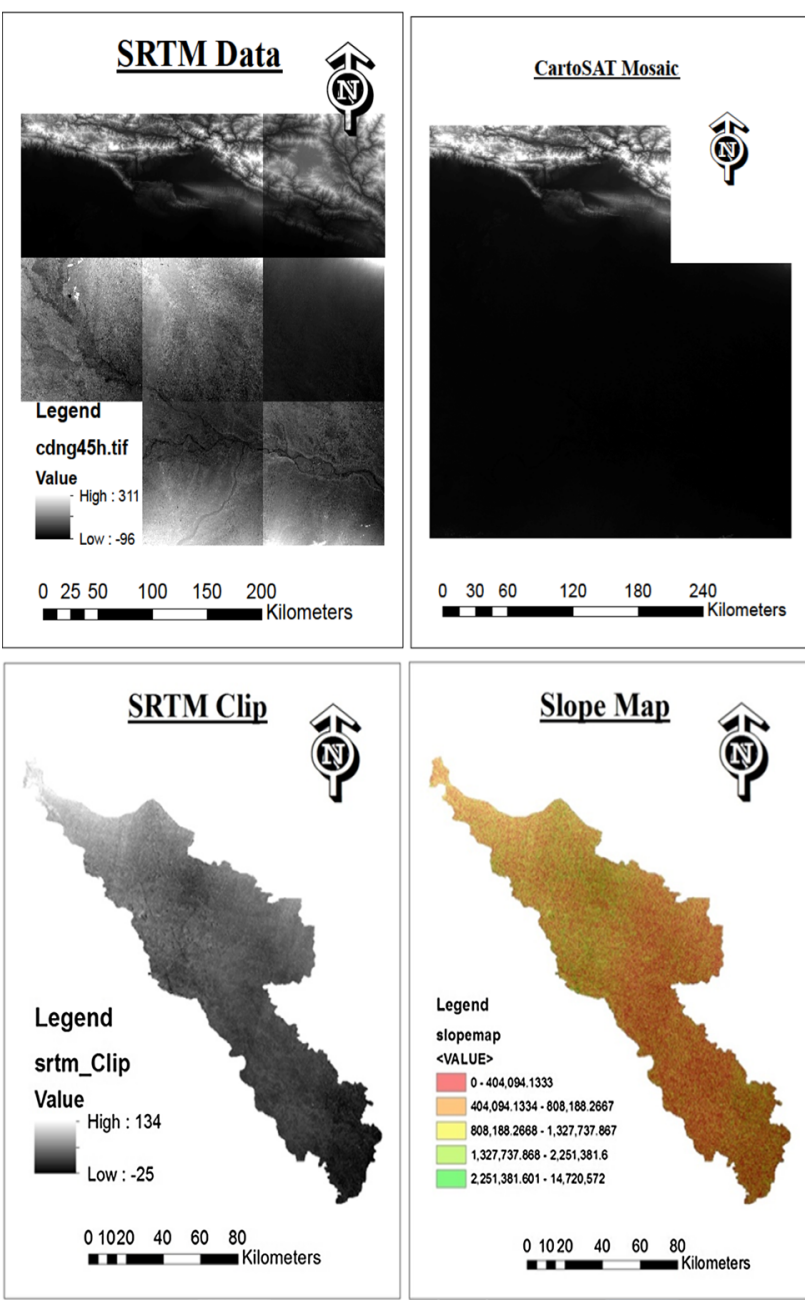

Fig. 3 Slope map derived from SRTM data

\section{Study area}

The study area is located at Himalayan foot hills in Northern part of Indian Territory. Gandak river is a major northern tributary of river Ganga. A major irrigation project, namely Gandak river project, is incepted by the Indian Government with an objective to utilize Gandak water for optimum agricultural use. This project is sub-divided into two commands, namely the Eastern Gandak Command Area and Western Gandak Command Area. The Eastern Gandak Command Area (EGCA) is chosen as the study area for this work. EGCA covers primarily four districts of Bihar state within Indian territory, namely Vaishali, Muzaffarpur, East Champaran and West Champaran, and are located within latitude $27.436288^{\circ} \mathrm{N}$ to $25.644601^{\circ} \mathrm{N}$ and longitude within $83.84902^{\circ} \mathrm{E}$ to $85.581423^{\circ} \mathrm{E}$ having an aerial extent of $9453 \mathrm{~km}^{2}$. The length of main canal, namely Tirhut Main Canal (TMC), is around $241 \mathrm{~km}$. All channels of the project are proposed to be unlined resulting in considerable seepage loss while in operation. The essential information and relevant data with regard to Gandak river project have been acquired from Water Resources Department, Government of Bihar (http://wrd.bih.nic.in/).

\section{Cropping pattern}

A major part of the cropping area (88.3\%) is paddy-growing region, namely rice, wheat, maize, barley and pulses. Rice is the most predominant crop (43.2\%) followed by wheat $(28.5 \%)$, maize $(7.8 \%)$, pulses $(7.0 \%)$, sugarcane $(5.4 \%)$, potato $(2.0 \%)$, vegetables $(1.7 \%)$, oil seeds $(1.6 \%)$, other food grains $(1.3 \%)$, barley $(0.5 \%)$, spices $(0.4 \%)$ and other crops $(0.6 \%)$ of the cultivated area. The cultivable area is $6880 \mathrm{~km}^{2}$ of $9453 \mathrm{~km}^{2}$ of total command area in the study region. The location map of the study area is presented in Fig. 4.

\section{Climate}

The ten-year average annual rainfall of the region is recorded as $1218 \mathrm{~mm}$ that is reasonably significant and noticeable. Vaishali district of the region receives the least average rainfall that is $1042 \mathrm{~mm}$ per annum, while West Champaran receives highest average rainfall of $1448 \mathrm{~mm}$ per annum. Almost 85 percentage of the total annual rainfalls is received during the southwest monsoon period from mid-June to mid-October of each year. Remaining 10 percentage occurs during summer and $5 \%$ occurs during November to February of the year. The maximum temperature recorded is around $42{ }^{\circ} \mathrm{C}$ during summer (March to June). Average relative humidity recorded in the morning and the evening are $67 \%$ and $59 \%$, respectively. The topography of the area is plain with quite a few undulated landscapes in the hilly tracts adjoining Himalayan range in West Champaran district. The slope is from north-west to south-east and gradually flattens from 1 in 1500 to 1 in 20,000 .

\section{Land use land cover}

Forest land cover is only 3.42 percentage of the total study area. The area under agriculture is 72.76 percentage. 4.44 percentage of the total area is covered with water, and the remaining 19.4 percentage is urban and non-agricultural land. Soil texture varies with the physiography. The texture in the upland consists ofsandy loam, while the predominant soil texture of mid uplands is silt loam and low lands have silty clay loam, sandy loam and clay loam as dominant textures. 
Fig. 4 Location map of the study area

\section{Location of Study Area}

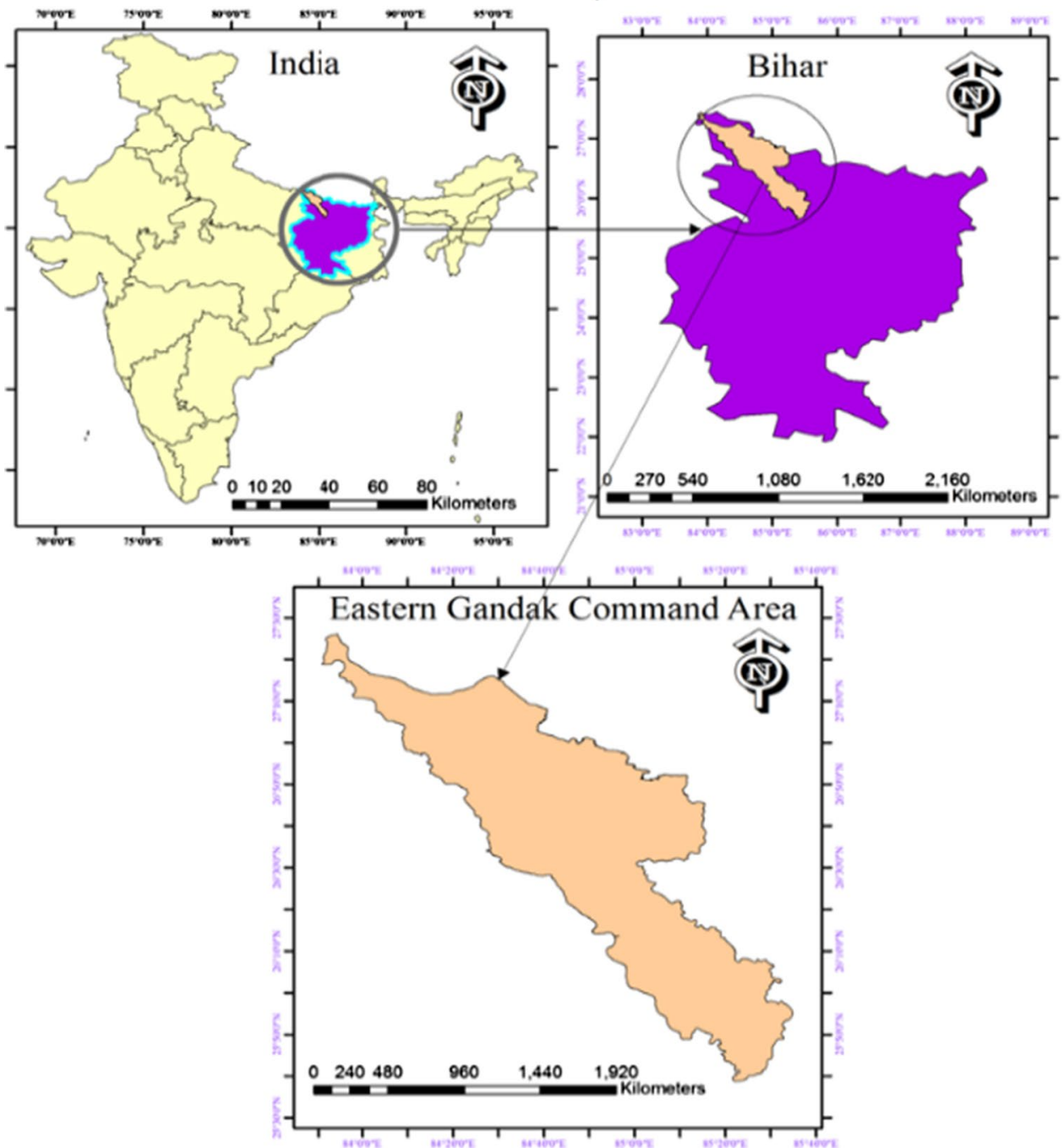

\section{Materials and methods}

The monthly mean temperature, rainfall, potential evapotranspiration and reference crop evapotranspiration data including monthly relative humidity and wind speed data were acquired from Indian Metrological Department (IMD) (http://indiawaterportal.org). The satellite data such as $C A R$ TOSAT-1, LANDSAT and SRTM data have been used in the present study for spatial mapping using relevant chosen parameters (Fig. 5). The climate data such as temperature and rainfall as well as soil factors have also been acquired from Indian Meteorological Department, Govt. of India (IMD).

Soil parameters such as soil depth, texture and moisture holding capacity are used in the present study. Since the data available for depth and moisture holding capacity were qualitative (low-high format), the data were converted to their numeric values with reference to Food and Agriculture Organization $(F A O)$ standards. After performing the geo-statistical analysis of the point data, the interpolated soil map for the study area was extracted. Undisturbed random soil sampling was done. SRTM data were further used for the generation of TIN (Triangulated Irregular Network) and DEM (Digital Elevation Model). To analyse the waterholding capacity, eight soil samples at a depth of 6-8 inches were collected. Soil depths and rainfall data for sixty blocks in the study area for October 2016 are collected and represented location wise graphically in Fig. 6.

The crop water requirement is defined as the depth of water required to meet the water loss through evapotranspiration of a disease-free crop, growing the large fields under uncontrolled soil conditions including soil water and fertility as well as achieving full production potential under the given growing environment. The crop water requirement varies with crop type and duration. Crop water requirement includes all sources of water used for crop growth such as precipitation, water from irrigation project as well as available groundwater. Therefore, net water requirement from canal network is computed through 

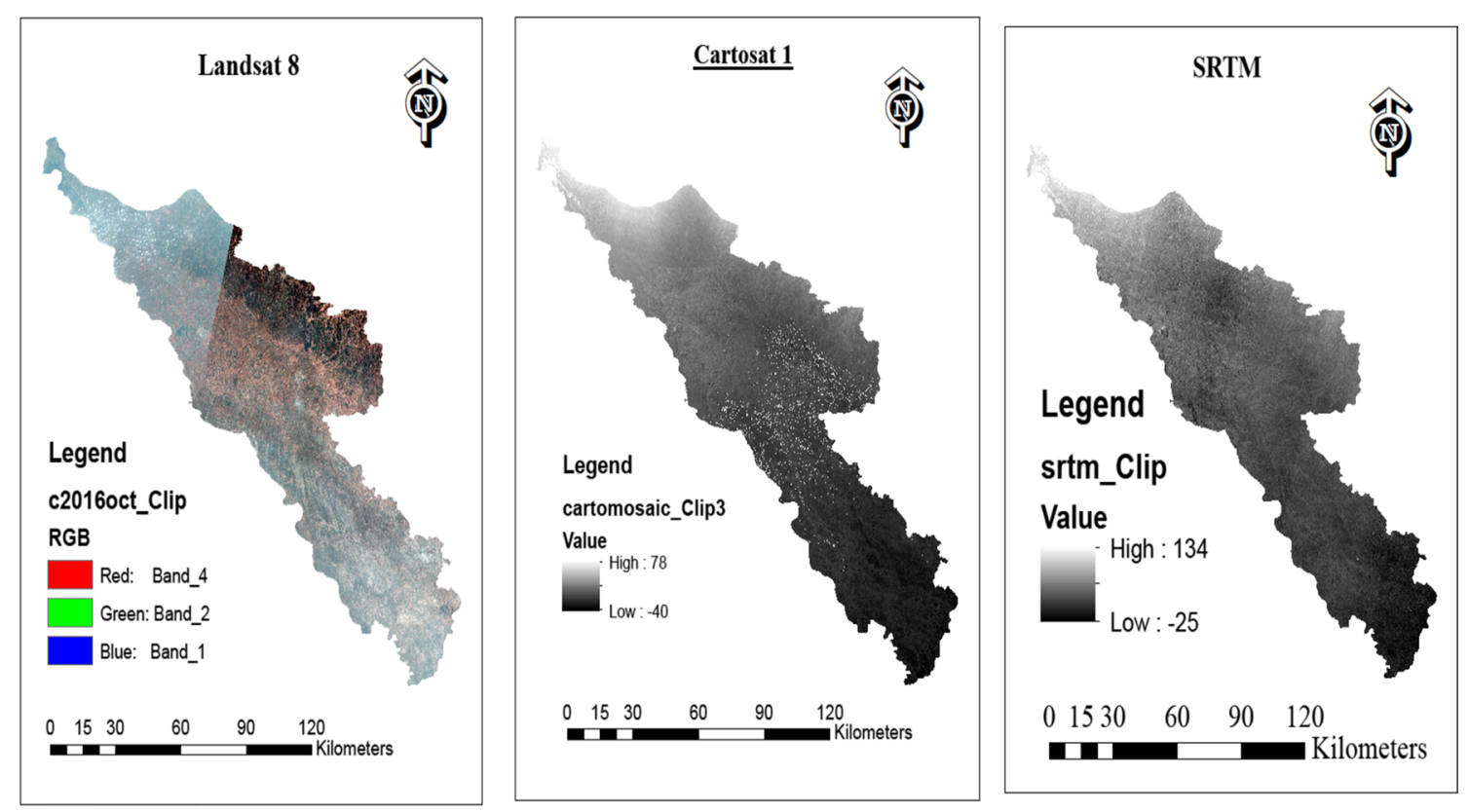

Fig. 5 Satellite data used (Landsat 8, Cartosat-1 and SRTM)

Fig. 6 Soil depths and rainfall data for sixty blocks in the study area for October 2016
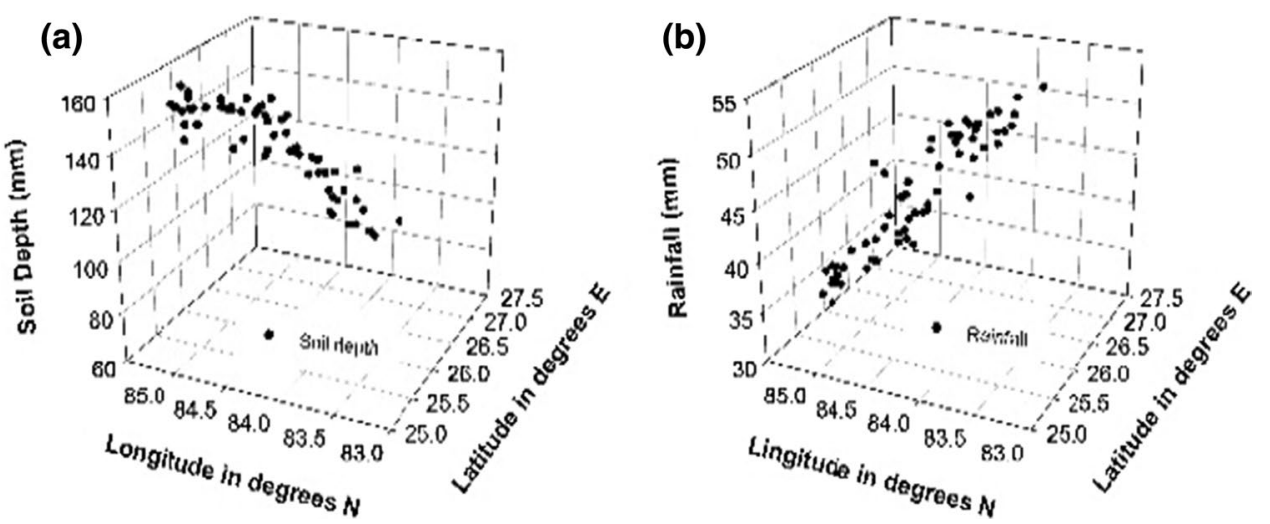

deducting water available from precipitation and groundwater resource. The specific crop evapotranspiration is calculated by multiplying potential evapotranspiration $\left(\mathrm{ET}_{0}\right)$ by the crop coefficient as follows (Doorenbos and Pruitt 1975).

$\mathrm{ET}_{\mathrm{C}}=K_{C} * \mathrm{ET}_{\mathrm{O}}$

where $\mathrm{ET}_{\mathrm{C}}$ is crop evapotranspiration in mm/day and $K_{\mathrm{C}}$ is the specific crop coefficient for the crop type.

The Hargreaves potential evapotranspiration (PET) method is used to compute the potential evapotranspiration using Eq. 4 (Hargreaves and Samani,1982).

$(P E T)=0.0075 \cdot R_{s} \cdot C_{t} \cdot \sqrt{\Delta t} \cdot T_{\mathrm{avg}}$

where $R_{S}=$ total incoming extra-terrestrial solar radiation, $C_{t}=$ temperature reduction coefficient, $\Delta t=$ difference between mean monthly maximum and mean monthly minimum temperature and $T_{\mathrm{avg}}=$ mean temperature.

The value of crop coefficient is dependent on crop characteristics, planting, stage of growth and climatic conditions. The crop coefficient has to be decided for each crop for every fortnight of its growth period. Remotely sensed normalized difference vegetation index (NDVI) is used to determine the crop coefficient. The crop coefficient is calculated using the following equation (Rocha et al. 2010; Inamdar et al. 2016)

$K_{C}=1.25 * N D V I+0.2$

where NDVI can be computed using the following equation (Melesse et al. 2001; Kumbhar et al. 2014). 
$N D V I=\frac{N I R-R}{N I R+R}$

where $R$ and NIR stand for the spectral reflectance measurements acquired in the red (visible) and near-infrared regions, respectively. This spectral reflectance is themselves ratios of the reflected over the incoming radiation in each spectral band individually; hence, they take on values between 0.0 and 1.0. Thus, NDVI itself thus varies between -1.0 and +1.0 . Agriculture data were acquired including crop statistics in the study area for paddy crop for the year 2016 from Water Resources Department, Government of Bihar. Remotely sensed normalized difference vegetation index $(N D V I)$ is a helpful measure of photosynthetic life at photographic scales and was used to work out the productivity. Reflectance values for the red $(R)$ and the adjoining nearinfrared $(N I R)$ were used to predict the normalized difference vegetation index (NDVI). ArcGIS software spatial analyst tool was used to create $N D V I$ map, crop coefficient map and finally crop evapotranspiration map using LANDSAT mosaic image presented in Fig. 7.

Hybrid classification is done to get land use land cover ( $L U L C$ ) map for the study area using mosaic image of LANDSAT. Hybrid classification includes the advantages of both supervised and unsupervised classification. From LULC map, area covering paddy crops were extracted. Hybrid classification map and corresponding area extracted classification, namely forest cover, water, urban and agricultural area, are presented in Figs. 8 and 9.
The geo-statistical analysis using the GIS tools for soil and climate factors was prepared through interpolation using inverse distance-weighted (IDW) method with the available data. The method evaluates the factors using nearest neighbourhood technique. The corresponding prepared maps for soil and precipitation are presented in Fig. 8 with bar chart representation in Fig. 9.

In this way, six input maps, namely NDVI, agriculture, slope, soil, precipitation and aridity index maps, were generated. Furthermore, reclassification was done to standardize the data set, for example, agriculture was reclassified on a scale of 2, indicating 1 as present and 2 as absent, respectively. Similarly, precipitation reclassified on a scale of 3 , with 1 is as low, 2 as moderate and 3 as high. Soil, aridity, slope and NDVI are reclassified on similar fashion based on the scale of 6 , where 6 represents the highest intensity and 1 corresponds to the lowest for a given features. Reclassified maps thus prepared using the GIS tools are presented as Figs. 10 and 11.

Principal component analysis (PCA) was used as a data exploration and decrease technique for getting the principal information from large data sets. It was used to shorten the data by extracting the variables in terms of a smaller number of fundamental structures as principal components. A correlation matrix was created for agriculture with each of the six parameters produced. The sum of the values from the correlation matrix was obtained, and their percentage values were computed. These values were used as weights for the weighted overlay analysis.

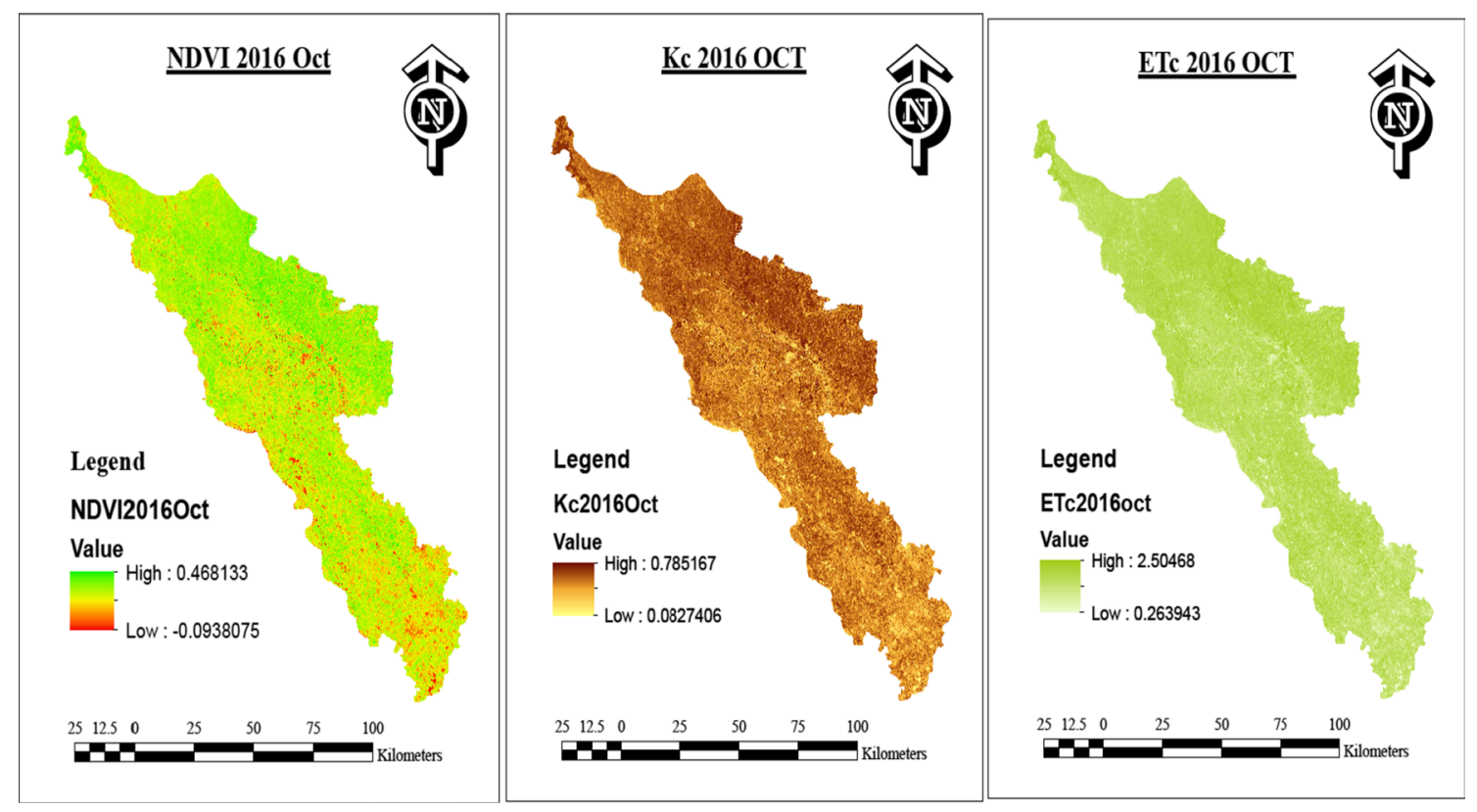

Fig. 7 Reclassification of rainfall, soil depth and aridity index maps 

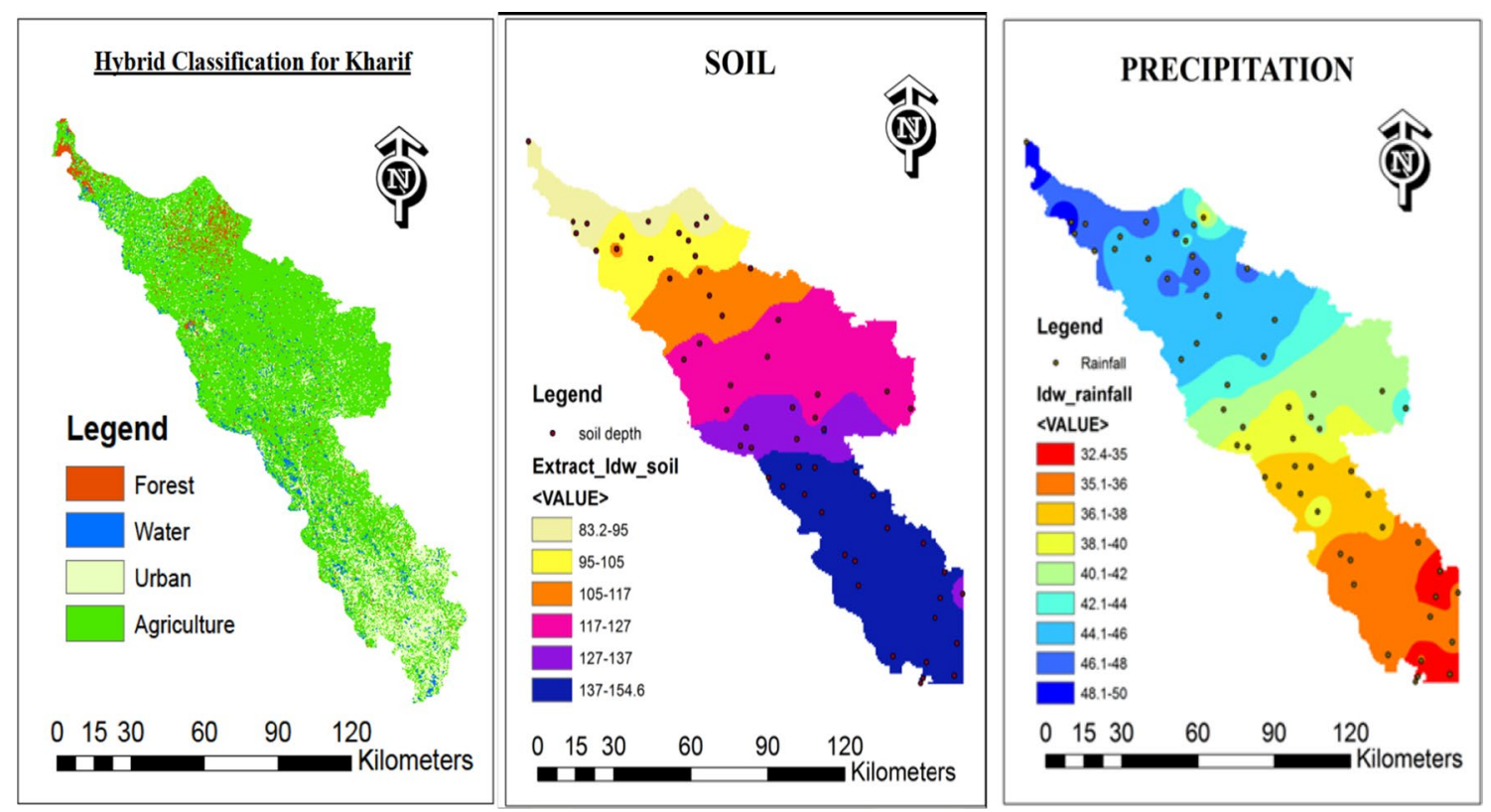

Fig. 8 Generated hybrid classification, soil map and precipitation maps using geo-statistical analysis

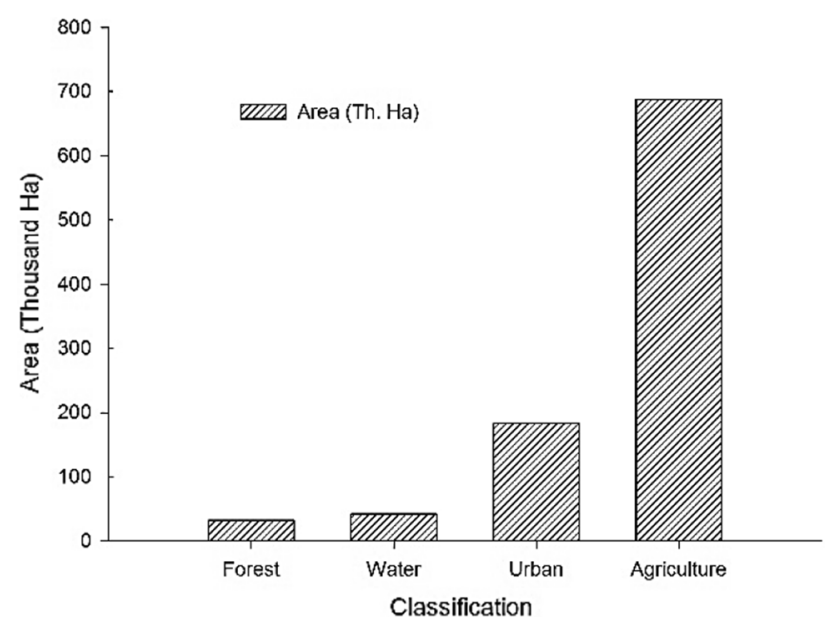

Fig. 9 Hybrid classification

Weighted overlay analysis: The linear weighted model was used as the final step in order to conduct weighted overlay analysis. The weights were allocated to the raster maps. For each polygon, the weighted sum of allocated weight values was computed. Resultant score for each polygon is indicative of its productivity with respect to each other. Finally, all data of high significance were written in a text file, and the outcome of the model is graphically represented. The principal component analysis classification (Fig. 11) was used for the representation.

For conducting analysis (schematic diagram for weighted overlay analysis model is presented in Fig. 12), thematic layers were prepared using GIS tool and each layer were reclassified into different required classes. The reciprocal matrix using pair comparison method was generated. Using reciprocal matrix, normalized matrix was further generated. Score was assigned for each attribute by stretching the values of priority vector to the scale of $1-5$. Percentage influence for each parameter was computed by converting priority vector to percentage, and thus, final layer using weighted overlay analysis was generated (Fig. 13).

\section{Results and discussion}

The weighted overlay analysis of the aforementioned six parameters to compute agricultural productivity for the study region is depicted in Fig. 13.

The different grades of land visible vividly can be identified in relation to agricultural productivity. It is readily inferred that agriculture potential decreases as one moves from extreme northern part of the region to the extreme southern part.

The evaluated agricultural potential was the highest in north-central part of the study area. Moreover, aridity index that measures dryness is also found to be the lowest in this region which suggests moderate gradient and mostly deep clayey soil distribution. Low agricultural potential obtained in most of the southern part of the study area where aridity index value is on higher side additionally with steeper gradient as well as least irrigation for the same soil cover. Out of the six parameters those were selected to compute

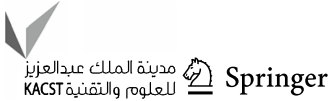



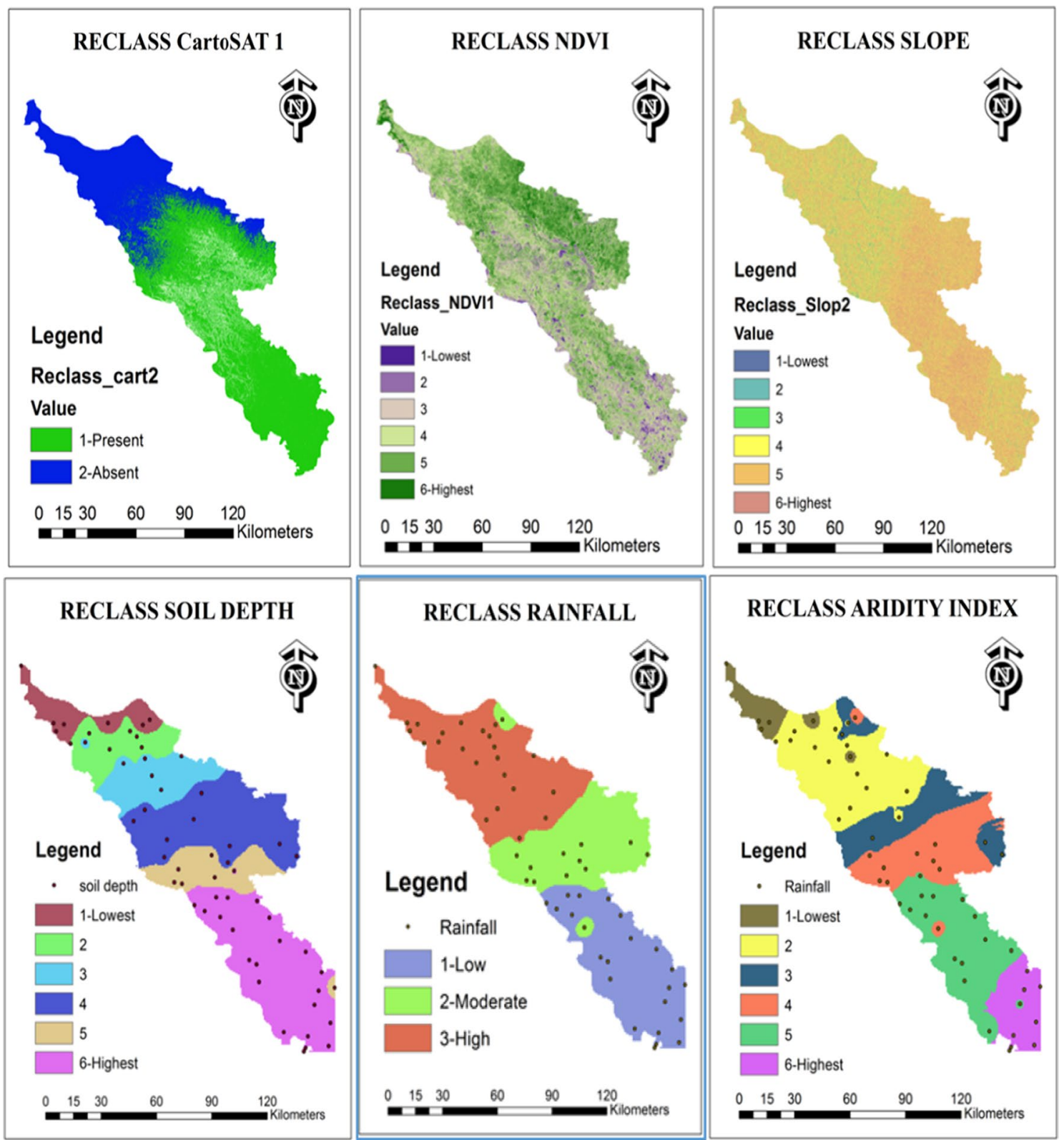

\section{RECLASS ARIDITY INDEX}

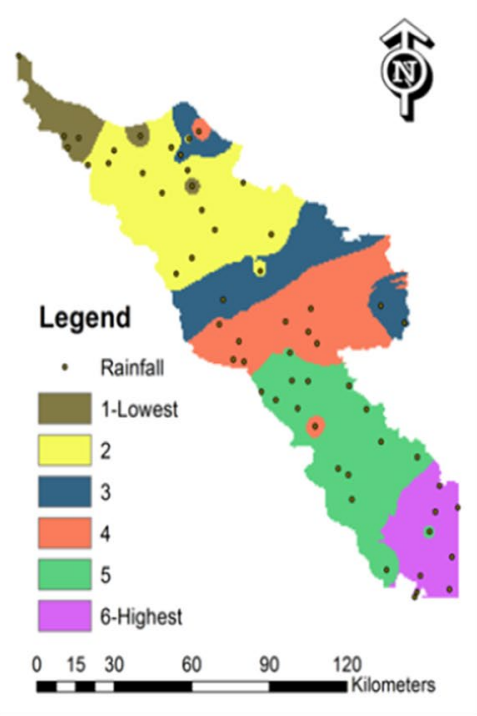

Fig. 10 Reclassification of rainfall, soil depth and aridity index maps

agricultural productivity, two parameters, namely aridity and slope, were found to be inversely related whereas other four parameters, namely productivity, irrigation, soil depth and rainfall, were found to be directly related. The assessed irrigation potential is given in Table 2 .

Satellite imagery data, namely CARTOSAT- 1 with high resolution, were used to analyse canal network of the proposed project to study the prevailing gaps present in the irrigation infrastructure. The results infer that factors affecting moisture content of the soil have major influence in determining the agricultural potential for paddy crops in the study area where the influence of aridity is counter balanced by the canal network and a second-order tributary to Gandak river. The soil for the region is clayey soil. Depth of soil plays an important role in its water-holding capacity. Since the deeper soils lie in the south-central and southern region, extension of irrigation into those areas will likely to enhance its agricultural potential from the current 73 percentage. The agricultural potential can also be optimized in the study area using properly informed and efficient rotation of irrigation water. The assessed agriculture potential is presented as Table 3 . 


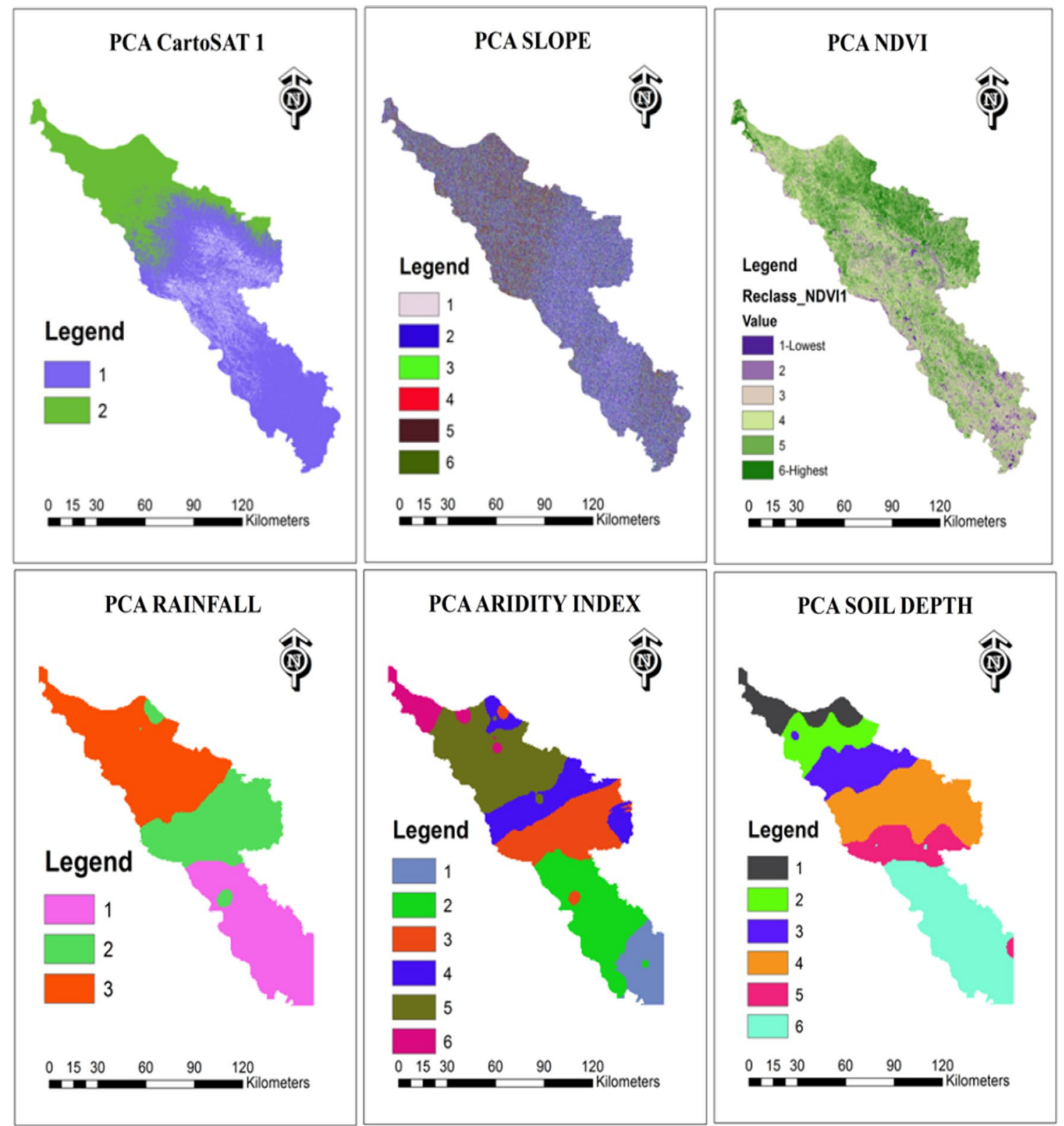

Fig. 11 Principal component analysis for all six parameters

\section{Conclusion}

From the Results and discussion section, different conclusions are made, and some recommendations are listed on the irrigation as follows:

(i) The difference in proposed IP and satellite IP is apparently due to land acquisition problem. It can be readily inferred that north-central region with relatively higher elevation, as well as soil cover with low water-holding capacity of the study area, is predominantly characterized by paddy crops. Perennial crops are found to be grown around the vicinity of canals. It is apparent that these double (perennial) crop usually grow on medium to low-lying areas with comparatively higher water-holding capacity. Hence with adequate irrigation, these crops are likely to be highly benefited resulting in enhanced productivity.

(ii) Improvement in drainage facilities is warranted in the study region to recover the wetland/drainage congested areas and must be brought under cultivation. This would facilitate enhancing the area under paddy cultivation and increasing agricultural production, for better livelihood of the people.

(iii) Satellite-based data analysis and remote sensing technique can be very useful for enhanced planning 
Fig. 12 Weighted overlay analysis model

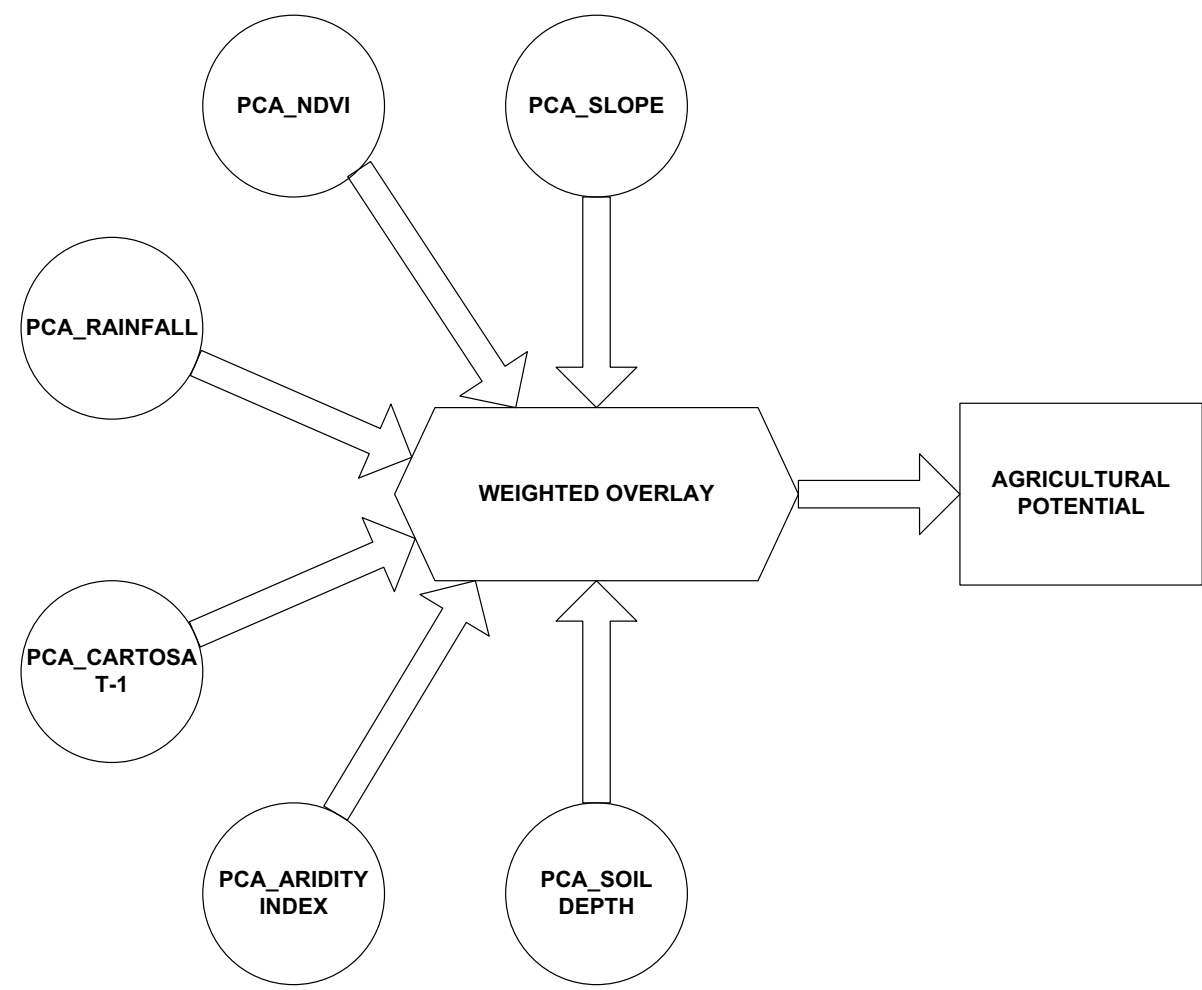

\section{AGRICULTURE POTENTIAL}
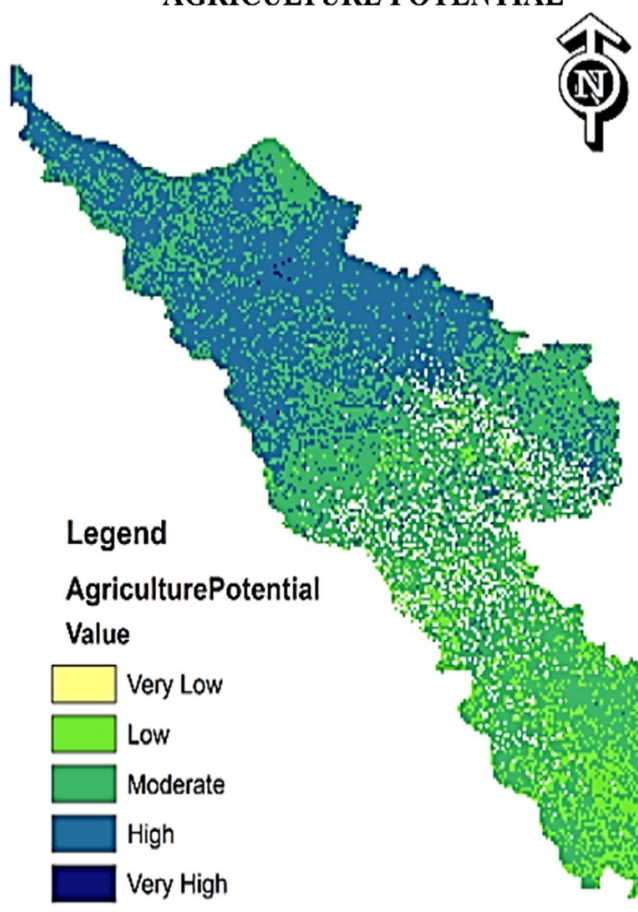

$0 \quad 15 \quad 30$

60 90 120
Table 2 Irrigation potential (IP) assessment

\begin{tabular}{ll}
\hline Classification & $\begin{array}{l}\text { Area } \\
\text { (thousand } \\
\text { Ha) }\end{array}$ \\
\hline Proposed IP & 960 \\
Satellite IP & 923 \\
CCA & 688 \\
GCA & 945 \\
\hline
\end{tabular}

Table 3 Agriculture potential (AP) assessment

\begin{tabular}{lc}
\hline Agriculture potential & $\begin{array}{l}\text { Area } \\
\text { (thousand } \\
\text { Ha) }\end{array}$ \\
\hline Very low & 0.480 \\
Low & 134.24 \\
Moderate & 477.30 \\
High & 333.00 \\
Very high & 6.70 \\
\hline
\end{tabular}

tools for optimum surface/groundwater uses, with a view to optimize on-farm decision making, real-time monitoring and managing farm and irrigation operations.

Fig. 13 Map representing weighted overlay analysis model 
Acknowledgement For the present study, data are provided by Water Resources Department (WRD), Government of Bihar, India, and Indian Meteorological Department, Govt. of India which is gratefully acknowledged here.

Funding Data used for this study were procured from Governmental database which has been duly acknowledged in the manuscript text. As this work is part of field-specific research conducted within the institutional resources, hence external funding resource part is absent.

\section{Compliance with ethical standards}

Conflict of interest The authors declare that they have no conflict of interest.

Open Access This article is licensed under a Creative Commons Attribution 4.0 International License, which permits use, sharing, adaptation, distribution and reproduction in any medium or format, as long as you give appropriate credit to the original author(s) and the source, provide a link to the Creative Commons licence, and indicate if changes were made. The images or other third party material in this article are included in the article's Creative Commons licence, unless indicated otherwise in a credit line to the material. If material is not included in the article's Creative Commons licence and your intended use is not permitted by statutory regulation or exceeds the permitted use, you will need to obtain permission directly from the copyright holder. To view a copy of this licence, visit http://creativecommons.org/licenses/by/4.0/.

\section{References}

Ahmad SR, Ahmad U, Masood A (2013) Geo-spatial techniques in selection of potential dam site. Pakistan J Sci 65(1):158-166

Al Barik Punit, Mazumdar Mriganka, Dutta Mrinal Kr (2017) A study on hydroelectric and irrigation potential of Dikhow river, Assam. ADBU J Eng Technol 6(2):82-87

Al-Ghobari HM, Mohammad FS (2011) Intelligent irrigation performance: evaluation and quantifying its ability for conserving water in arid region. Appl Water Sci 1(3-4):73-83

Camilo C (2003) Use of evapotranspiration model and geographic information system (GIS) to estimate the irrigation potential of the Trasvase System in the Santa Elena Peninsula, Guayas, Ecuador, University of Florida

Chatterjee C, Kumar Rakesh, Mani Pankaj (2003) Delineation of surface waterlogged areas in parts of bihar using IRS-1C LISS-III data. J Indian Soc Remote Sens 31(1):57-65

Chatterjee C, Kumar Rakesh Chakravorty B, Lohani AK, Kumar S (2005) Integrating remote sensing and GIS techniques with groundwater flow modeling for assessment of waterlogged areas. Water Resour Manage 19(5):539-554

Chowdary VM, Chandran RV, Neeti N, Bothale RV, Srivastava YK, Ingle P, Singh R (2008) Assessment of surface and sub-surface waterlogged areas in irrigation command areas of Bihar state using remote sensing and GIS. Agric Water Manag 95(7):754-766

Das S, Pardeshi SD (2018) Integration of different influencing factors in GIS to delineate groundwater potential areas using IF and FR techniques: a study of Pravara basin, Maharashtra, India. Appl Water Sci 8(7):197

Doorenbos J, Pruitt WO (1975) Guidelines for predicting crop water requirements, irrigation and drainage paper $24, \mathrm{FAO}$ of the United Nations, Rome

Gebremedhin MA, Kahsay GH, Fanta HG (2018) Assessment of spatial distribution of aridity indices in Raya valley, northern Ethiopia. Appl Water Sci 8(8):217

Hargreaves GH, Samani ZA (1982) Estimating potential evapotranspiration. J Irrig Drain Div 108(3):225-230

Inamdar P, Singh TP, Metha K, Kumbhar V (2016) Assessment of irrigation and agriculture potential of the Krishna river basin using geospatial techniques. Indian J Sci Technol 9(44):1-9

Ismail M, Abdel Ghaffar MK, Azzam MA (2012) GIS application to identify the potential for certain irrigated agriculture uses on some soils in Western Desert, Egypt. Egypt J Remote Sens Space Sci 15(1):39-51

Kumbhar V, Choudhury S, Sen A, Singh TP (2014) Assessment of irrigation and agriculture potential using geospatial techniques: a case study of "Bhima-Ujjani Project. Proc Soc Behav Sci 157:277-284

Magd AE, Tanton T (2005) Remote sensing and GIS for estimation of irrigation crop water demand. Int J Remote Sens 26(11):2359-2370

Melesse AM, Jordan JD, Graham WD (2001) Enhancing land cover mapping using landsat derived surface temperature and NDVI. In: Conference paper: proceedings of the world water and environmental resources congress, Orlando, Florida. https://doi. org/10.1061/40569(2001)439

Rocha J, Perdigaob A, Meloa R, Henriquesh C (2010) Managing water in agriculture through remote sensing applications. Remote Sens Sci. Education of Natural and Cultural Heritage, pp 223-229

Singh RK, Irmak A, Irmak S, Martin DL (2007) Satellite remote sensing based estimation of land surface evapotranspiration in great plains. In: World environmental and water resources congress 2007: restoring our natural habitat, pp 1-10

WRI I, UNEP (1992) Global biodiversity strategy. World Resources Institute, Washington, DC

Publisher's Note Springer Nature remains neutral with regard to jurisdictional claims in published maps and institutional affiliations. 